\title{
Demand as Frequency Controlled Reserve
}

\author{
Xu, Zhao; Østergaard, Jacob; Togeby, Mikael
}

Published in:

IEEE Transactions on Power Systems

Link to article, DOI:

10.1109/TPWRS.2010.2080293

Publication date:

2011

Link back to DTU Orbit

Citation (APA):

Xu, Z., Østergaard, J., \& Togeby, M. (2011). Demand as Frequency Controlled Reserve. IEEE Transactions on Power Systems, 26(3), 1062-1071. https://doi.org/10.1109/TPWRS.2010.2080293

\section{General rights}

Copyright and moral rights for the publications made accessible in the public portal are retained by the authors and/or other copyright owners and it is a condition of accessing publications that users recognise and abide by the legal requirements associated with these rights.

- Users may download and print one copy of any publication from the public portal for the purpose of private study or research.

- You may not further distribute the material or use it for any profit-making activity or commercial gain

- You may freely distribute the URL identifying the publication in the public portal

If you believe that this document breaches copyright please contact us providing details, and we will remove access to the work immediately and investigate your claim 


\title{
Demand as Frequency Controlled Reserve
}

\author{
Zhao Xu, Member, IEEE, Jacob Østergaard, Senior Member, IEEE, and Mikael Togeby
}

\begin{abstract}
Relying on generation side alone is deemed insufficient to fulfill the system balancing needs for future Danish power system, where a $50 \%$ wind penetration is outlined by the government for year 2025 . This paper investigates use of the electricity demand as frequency controlled reserve (DFR), which has a high potential and can provide many advantages. Firstly, the background of the research is reviewed, including conventional power system reserves and the demand side potentials. Subsequently, the control logics and corresponding design considerations for the DFR technology have been developed and analyzed, based on which simulation models have been built using the DIgSILENT Power Factory. The simulation studies of different scenarios confirm that the DFR can provide reliable performance of frequency control. Furthermore, relevant issues regarding implementing DFR in reality have been discussed.
\end{abstract}

Index Terms-Demand side, frequency control, power system modeling and simulation, wind power.

\section{INTRODUCTION}

M AINTAINING the balance between the power generation and the demand, i.e., the system frequency, is a key issue in power system operation. Today, generation side resources including extra capacities from large generators and interconnection lines are primarily used for such purpose. Disconnection of demand, i.e., load shedding, is used as the last resort in emergency situation and whole areas are shed if the frequency drops below a very low limit, for example, $49.50 \mathrm{~Hz}$ or lower in the Nordic interconnected system [1].

Theoretically, the generation and demand can contribute equally to the frequency control as reserves. However, the demand has so far been largely underutilized. This is mostly because the current control paradigm was designed to procure services from several large power plants, with prejudices against demand side resources. The complexity of fulfilling the real-time monitoring requirement for many distributed, small sized loads, is considered the major obstacle to utilize the demand as reserves. Customer comforts and wear and tear are also concerned for end user appliances. Besides, the business

Manuscript received October 16, 2009; revised October 21, 2009, February 25, 2010, June 03, 2010, and August 07, 2010; accepted September 13, 2010. This work was supported by the Danish Public Service Obligation (PSO) research funding program, Project "Demand as Frequency Controlled Reserve", Grant no. 2005-2-6380. Paper no. TPWRS-00818-2009.

$\mathrm{Z}$. Xu is with the Department of Electrical Engineering, Hong Kong Polytechnic University, Hunghom, Kowloon, Hong Kong (e-mail: eezhaoxu@ polyu. edu.hk).

J. Østergaard is with the Centre for Electric Technology, Department of Electrical Engineering, Technical University of Denmark, DK-2800 Lyngby, Denmark (e-mail: joe@elektro.dtu.dk).

M. Togeby is with the Ea Energianalyse A/S, Frederiksholm Kanal 1, 1220 Copenhagen, Denmark (e-mail: mt@eaea.dk).

Color versions of one or more of the figures in this paper are available online at http://ieeexplore.ieee.org.

Digital Object Identifier 10.1109/TPWRS.2010.2080293 model is another critical concern when dealing with many small loads.

In fact, many electricity demands, though with small capacities, can be turned on and off as frequently, and rapidly as needed, rendering perfect capability to be used as fast reserves. By installing with a frequency sensor and appropriate control intelligence, those loads can respond autonomously to frequency variation and provide fast reserve to the system. Household appliances including electric heating, refrigerators, freezers, and water heaters are ideal candidates due to their considerable volume and the possibility of instantaneous switching off. Accurate monitoring of such resources (e.g., with online meters) may be impractical, but estimation is possible, which is consistent with how the demand is treated in the market dispatching today. Compared with traditional reserves, the DFR can deliver the same service plus additional benefits, e.g., faster response speed, potentially lower costs, well-dispersed in distribution network and pollution free, etc. [2], [3]. This is particularly important for countries like Denmark, where lack of balancing resources is foreseen as the major challenge to achieve $50 \%$ wind penetration by 2025 [4].

Efforts have been made in the field of using demand as reserves. In the past, utilities have long been operating load management programs [6]. In [7], a market-based demand management program using low frequency relay to control industrial loads is reported. A similar program is implemented in the New Zealand power system [8]. In Finland, 1000-MW demands from wood processing, chemical, and metal industry are used as frequency controlled as well as manual reserves [9]. These programs have, however, mainly focused on large size industry loads. A pilot project using the ComfortChoice technology for controlling air conditioners to provide reserve was carried out by the Long Island Power Authority in 2003 [10]. Due to the communication (two-way paging) system introduced, the reserve is activated relatively slow in about $90 \mathrm{~s}$.

The Pacific Northwest National Laboratory (PNNL) has suggested that individual household appliances suitable for temporary disconnection can provide fast reserve within seconds, e.g., refrigerators and air conditioners [11], [12]. Similar suggestions have been made in the U.K. [13]-[15]. The idea was presented as early as in 1979 [16]. Because the implementation requires little electronics at low costs [13], these ideas become more attractive recently.

This paper investigates use of electricity demands as a new measure for fast reserves including frequency controlled disturbance and normal ones. Section II reviews the status of active power reserves and frequency quality in the Nordic power system. In Section III, different DFR control logics and considerations have been made to address concerns of both power system and customers. Section IV develops the simulation models of DFR demands using DIgSILENT Power 


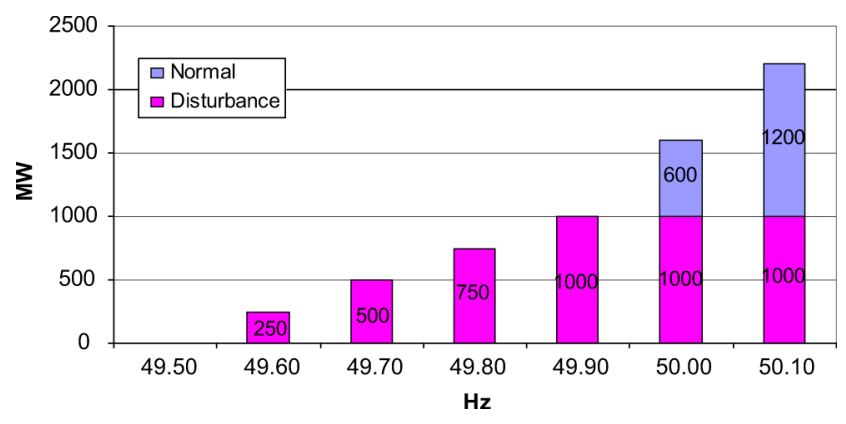

Fig. 1. Available frequency controlled normal and disturbance reserves in the Nordic power system.

Factory, based on which various scenarios have been simulated in Section V using practical power system models that demonstrates the DFR can perform as well as the generation side reserves. Section $\mathrm{V}$ outlines major conclusions as well as future scope of our research work. Furthermore, issues concerning monitoring method and market models for DFR have also been preliminarily discussed, yet to be continued in the future.

\section{BACKGROUND AND PROSPECTIVE}

\section{A. Status of Frequency Control in the Nordic Power System}

The Nordic system has been investigated to identify specific reserves that best suit the demand side. Other systems like the UCTE of mainland EU will be studied in the future. In the Nordic system that covers Eastern Denmark, Norway, Finland, and Sweden, reserves are classified as frequency controlled normal and disturbance reserves, and fast and slow active disturbance reserves that mainly differ in the activation time and frequencies [1]. The market for these reserves is introduced in [17].

Using demand as disturbance reserve is focused, and the option of using demand as normal reserve is also studied. Totally 1000-MW disturbance reserve must be procured by the Nordic TSOs, and in events of contingencies, the reserve must be activated automatically and linearly between 49.5 to $49.9 \mathrm{~Hz}$ [5]. The normal reserve deals with small frequency deviations in normal condition. It consists of up and down regulation for frequency variations between $49.9-50.1 \mathrm{~Hz}$, and is automatically activated within $2-3 \mathrm{~min}$. The volumes of required frequency controlled reserves are presented in Fig. 1, where the linear activation of the disturbance reserve is also shown. The fast and slow reserves are manually activated within or after 15 min, respectively, in order to replace the normal and disturbance reserves. All reserves are mainly provided by extra capacities from generators or HVDC lines, which are costly. E.g., the cost of 50-MW reservation on the Kontek HVDC between Eastern Denmark and Germany is estimated 125000 E/MW per year based on absolute differences in spot prices from November 2005 to May 2010, and reserved capacity (for frequency reserve) between the two areas.

From September 2009 at limited amount of frequency controlled disturbance reserves (in average $8 \mathrm{MW}$ ) has been purchased via a public auction. A reservation price is paid for blocks of $4 \mathrm{~h}$. The average reservation price (September

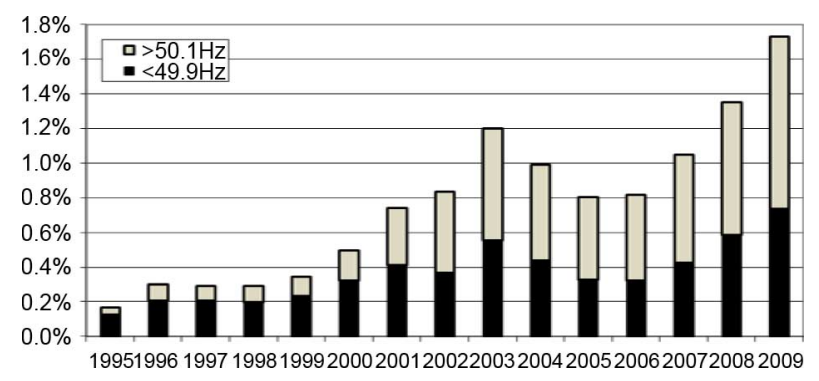

Fig. 2. Probability of frequencies over and under the normal range (49.9-50.1 $\mathrm{Hz}$ ). Data are provided by Swedish TSO Svenska Kraftnät, recorded from August 1995 to December 2009, at 1-min sample interval.

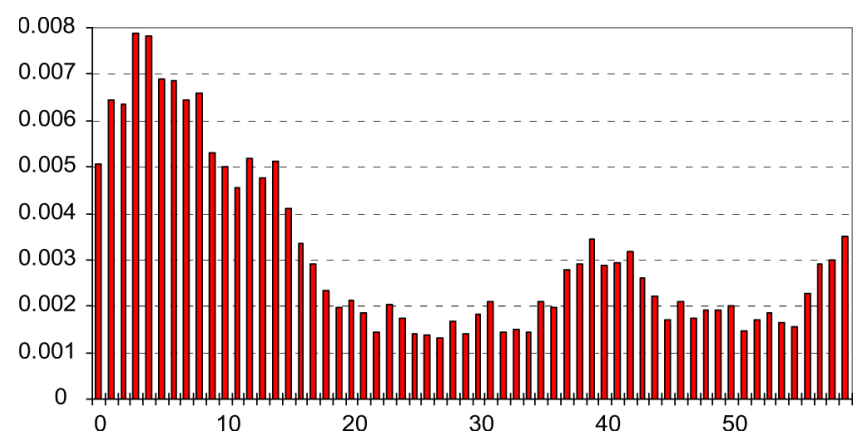

Fig. 3. Probability of frequencies under $49.90 \mathrm{~Hz}$ within the minutes of the hour. (The data of $>1.5$ billion samples are measured per $0.02 \mathrm{~s}$ for a year long period from April 2005 to March 2006 using phase measurement units installed in Eastern Danish grid [22], [23], and processed using DTU high performance computing facility [24].)

16, 2009 to August 1, 2010, Denmark East) has been 250000 E/MW per year.

Due to the frequency dependency, the total demand of the Nordic system reduces roughly by $200 \mathrm{MW}$ when the frequency drops from 50.0 to $49.5 \mathrm{~Hz}$ [1]. This is already considered into the reserve dispatching. Therefore, using the demands as fast reserves can be understood as to enhance their frequency response by deliberately switching on and off the non-essential ones. Well-designed, this can increase the stability of the electricity system.

The Nordic system has 49-GW hydropower in Norway Sweden and Finland, corresponding to $52 \%$ of its installed capacity, which is superior for frequency control [39]. Fig. 2 shows the probability of abnormal frequency $(<49.90 \mathrm{~Hz}$ or $>50.10 \mathrm{~Hz}$ ) has been increasing throughout the years. The probabilities since 2002 are above $0.8 \%$ which is more than a factor 3 higher than the goal $0.228 \%$ [18]. In 2003, low supplies of power with associated high prices can explain the peak of abnormal frequency in Fig. 2 [19]. Another reason for increased frequency excursions could be the reserve requirement was defined over 20 years ago and may not be up to date. Furthermore, some hydro plants are not originally designed to provide continuous frequency regulations [38].

Fig. 3 plots the probability of under-frequency versus the minute in an hour, where the probability appears much higher in the first $15 \mathrm{~min}$ of an hour compared to the rest. This can be well explained as the Nordic spot market is dispatched hourly, and consequently often intra-hour imbalances due to hourly shifts 
TABLE I

Potentials for Household Electricity Demand as Frequency Controlled ReSERve * [25]

\begin{tabular}{|c|c|c|c|c|c|}
\hline Demands & $\begin{array}{l}\text { Possible to disconnect } \\
\text { within } 1 \text { sec. of a under } \\
\text { frequency }\end{array}$ & $\begin{array}{l}\text { Possible to reconnect } \\
\text { instantly after frequency } \\
\text { has recovered }\end{array}$ & $\begin{array}{l}\text { Electronic control } \\
\text { installed }\end{array}$ & $\begin{array}{l}\text { Constant electricity } \\
\text { demand (aggregated) }\end{array}$ & $\begin{array}{c}\text { Potential MW } \\
\text { average (East } \\
\text { Denmark) } \\
\end{array}$ \\
\hline Refrigerators & + & $\div$ & $\div /+$ & + & 59 \\
\hline Freezers & + & $\div$ & $\div /+$ & + & 32 \\
\hline Air conditioners & + & $\div$ & $\div /+$ & $\div$ & - \\
\hline Water heaters & + & + & $\div$ & + & 31 \\
\hline Electric heating & + & + & $\div /+$ & $\div$ & 31 \\
\hline Washing machine & + & + & + & $\div$ & 24 \\
\hline Tumble drier & + & + & + & $\div$ & 18 \\
\hline Dish washer & + & + & + & $\div$ & 23 \\
\hline Total & & & & & 218 \\
\hline
\end{tabular}

exist. Such a market pattern is also verified by analyzing frequency data of UCTE and WECC systems, though relatively smaller probability of low frequency is observed due to a larger system size. The frequency analyses reveal that, besides failure events like generator outages, other factors like the market can cause abnormal frequencies as well. Notably, the wind penetration in the Nordic system is still marginal $(<2 \%)$. As Nordic countries, especially Denmark, are developing more wind energy, power balancing control will become critical in system operation. New measures such as the DFR technology should be applied in this context [4], [20], [21].

\section{B. Demand Side Prospective}

Many demands that can be disconnected quickly and shortly with limited disturbances to the appliances and customers comforts are suitable for DFR applications. The thermostatically controlled loads are especially ideal as they can act as energy storage. E.g., a few minutes of disconnection of electrical heating or cooling appliances will reduce or increase the temperature, but not to the extent to annoy the customers or harm the stored content. The average consumption for an individual appliance is limited, e.g., average consumption varies from $22 \mathrm{~W}$, for a high efficiency refrigerator, to $400 \mathrm{~W}$ for water heater in a four-person family. Electric space heating can be in the order of 1 to $3 \mathrm{~kW}$ per household. Nevertheless, the total compatible household demands constitute a large consumption according to our survey in Eastern Denmark in Table I, where $218 \mathrm{MW}$ of such demands is much larger than the required 78-MW disturbance reserve [25]. The potential in the overall Nordic system can be much higher due to the large use of electric heating in Norway, Sweden, and Finland.

Some compatible demands have constant consumption during all hours of the year, when a large number of refrigerators, freezers, or water heaters are considered. The variation due to user interaction is limited and the seasonal variation is little. Others like electric space heating have significant seasonal variation, but can be reliably predicted when aggregated. For appliances like washing machines and tumble driers, the daily variation is high, typically with no demand at night. For electric heating, disconnection and reconnection can happen instantaneously. For compressor type of demand, it is impossible to reconnect right after a disconnection. The typical compressor system in refrigerators and freezers are designed so they need a minimum 5-min resting period before next reconnection.
Besides household appliances, compatible loads are found in industrial sectors as well, e.g., electric ovens, ventilation systems, centrifuges, and aerating at waste water treatment plants. Especially, uninterruptible power supply (UPS) with battery storage and control system can implement the frequency reserve easily. It is estimated that in Danish companies 96-MW demand can be interrupted with the shortest notice of $5 \mathrm{~s}$ [21].

Many modern appliances are equipped with advanced electronic control, potentially useful when implementing frequency control. In some modern washing machines and tumble driers, possibilities of stopping and delaying the process already exist. In these cases, the cost of integrating the frequency control will be limited. In other cases, like water heaters, a mechanical thermostat is normally used to control the temperature and higher investment cost for frequency control can be foreseen.

Traditional reserve can be very costly, e.g., the primary and disturbance reserves in West and East Denmark are 22 and 8 $\mathrm{k}$ E/MW/year, respectively, in 2007 [26]. With an estimated production cost of the frequency control circuit of $20 €[12]$, the cost of reserve from DFR is roughly $3.2 \mathrm{k} \in / \mathrm{MW} / \mathrm{year}$ for the $1-\mathrm{kW}$ appliance, $1.6 \mathrm{k} \in / \mathrm{MW} / \mathrm{year}$ for the $2-\mathrm{kW}$ appliance, based on eight-year lifetime and an annual interest rate of $6 \%$. Here the annuity values are calculated by

$$
A=C \frac{R(1+R)^{n}}{(1+R)^{n}-1}
$$

where $A$ is annuity, $C$ is the initial cost, $R$ is the discount rate, and $n$ is payment period in years.

\section{DFR CONTROL LOGICS}

The DFR technology is to flexibly turn on or off electricity loads in response to frequency variations to provide normal or disturbance reserves. This can be implemented as an external control box or integrated within the electric appliances. The control should be designed considering the requirements of power systems, and the special features of the appliances, etc. Two types of control logics to switch on/off demands directly or indirectly are developed. Fig. 4 shows the control scheme with three stages.

1) The scheme starts with measuring the frequency at a time step, e.g., $0.02 \mathrm{~s}$. A moving average filter of a length, e.g., $0.5 \mathrm{~s}$, can be used to reduce measurement noise. This will be implemented with a sliding window algorithm for continuous measurement. 


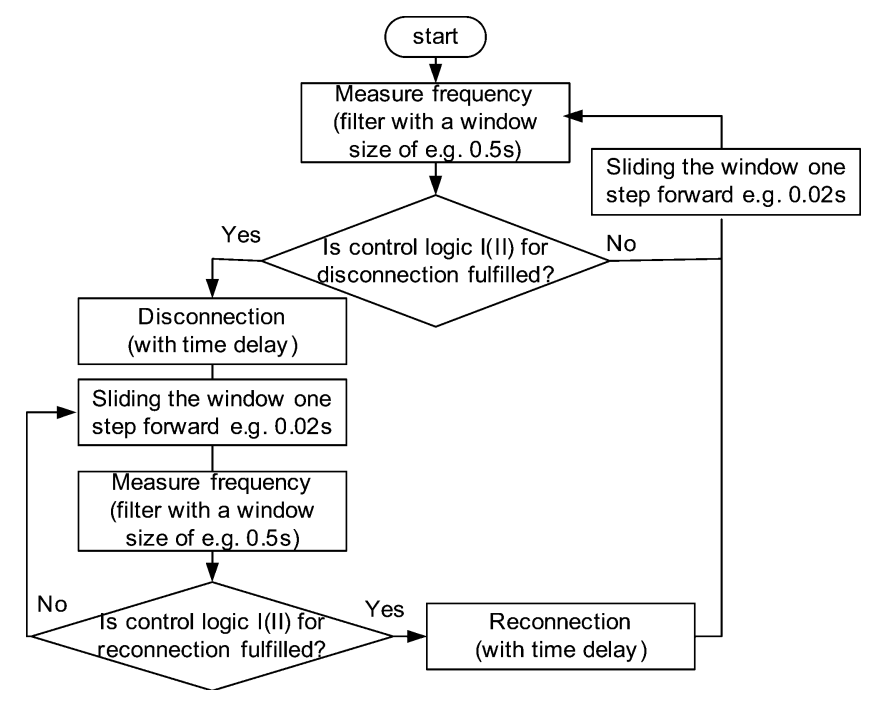

Fig. 4. Overview of the DFR control scheme.

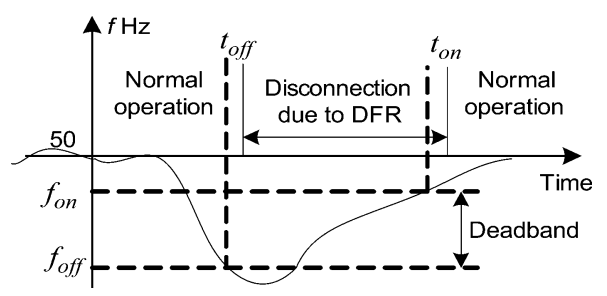

Fig. 5. Illustration of DFR Type I control and critical parameters.

2) Disconnection with delay will be activated based on the comparison of the measurement and the disconnection criterion. Otherwise, the scheme continues to the next cycle.

3) After disconnection, the scheme continues to measure and compare the frequency with the reconnection criteria. If satisfied, the appliances will be reconnected back to the grid after a certain delay.

\section{A. DFR Control Logic Type I}

The Type I disconnects and reconnects electric appliances, e.g., a water heater to the grid when system frequency falls and recovers, respectively [2]. The reconnection frequency set point $f_{\text {on }}$ should be equal to or higher than the disconnection set point $f_{o f f}$, to give a hysteresis that can prevent oscillatory behaviors and consequently excessive wear outs to the appliances [2] (Fig. 5). Time delays $t_{o f f}$ and $t_{o n}$ are introduced in the disconnection and reconnection to deal with the measurement noise and other considerations.

The disconnection set point can be designed in accordance with the specifications of the targeted reserve, e.g., 49.90 and $49.95 \mathrm{~Hz}$ for frequency controlled disturbance and normal reserves, respectively, in the Nordic power system. To achieve proportional activation and prevent over-activation of DFR, randomized set points within, e.g., [49.50, 49.90] $\mathrm{Hz}$ can be applied to a large group of appliances. For the thermostatically controlled loads, two variant designs are developed as in Table II. When reconnected, Type $I_{b}$ always starts "on", while Type $I_{a}$ starts according to the appliance temperature, e.g., if the temperature is above (below) the lower limit, the heaters will starts with "off" (on). They can give different impacts to the power system.
TABLE II

VARIANT DESIGNS FOR DFR TYPE I CONTROL

\begin{tabular}{cl}
\hline \hline Type & How does the control start after reconnection \\
\hline$I_{a}$ & Start according to the temperature at reconnection \\
$I_{b}$ & Always start on at reconnection \\
\hline
\end{tabular}

\section{B. DFR Control Logic Type II}

The Type II control is specially designed for thermostatically controlled loads to indirectly switch the loads by adjusting the temperature set points [13]. For example, a linear relationship between the temperature set points and system frequency can be used for electric heating loads, i.e.,

$$
\begin{aligned}
T_{\text {high }} & =T_{\text {high }}^{\text {normal }}+k f\left(f-f_{0}\right) \\
T_{\text {low }} & =T_{\text {low }}^{\text {normal }}+k f\left(f-f_{0}\right)
\end{aligned}
$$

where $T_{\text {high }}^{\text {normal }}$ and $T_{\text {low }}^{\text {normal }}$ are nominal high and low temperature set points, $f_{0}$ is the nominal frequency which is $50 \mathrm{~Hz}$ for the Nordic system, $f$ is the measured frequency, and $k f>0$ is the coefficient of frequency change in ${ }^{\circ} \mathrm{C} / \mathrm{Hz}$.

Consider a large number of electric heaters in normal operation; they can reach the equilibrium status with their temperatures well distributed within the upper and lower limits. The number of on and off units will become relatively stable, so as the total consumption power of "on" units. If the frequency varies by $\Delta f$ and if $k f \Delta f \leq\left(T_{h i g h}^{\text {normal }}-T_{\text {low }}^{\text {normal }}\right)$, the power decrease or increase due to Type II control can be estimated by (4) and (5), respectively:

$$
\begin{aligned}
& \frac{k f \Delta f}{T_{\text {high }}^{\text {normal }}-T_{\text {low }}^{\text {normal }}} \times P \times \lambda \\
& \frac{k f \Delta f}{T_{\text {high }}^{\text {normal }}-T_{\text {low }}^{\text {normal }}} \times P \times(1-\lambda)
\end{aligned}
$$

where $P$ is total installation power of heaters, $\lambda$ represents the percentage of on heaters. If the frequency falls or rises, the control will start disconnecting or reconnecting appliances close to the end of their on or off cycle. Due to the internal thermal control, the disconnected appliances will be reconnected sooner or later regardless of the frequency. Therefore, Type II control can be less disturbing to the end-user as it only changes the appliance operation cycles for providing reserves. Because not all heaters are always on, the reserve from Type II has to be realized by aggregating many of such appliances, of which only a small portion will be affected in most low or high frequency events, with limited disturbance to customer comforts.

Proper design of $k f$ should consider the requirements from power systems and appliances, etc. Moreover, different $k f$ values can be used for different frequency deviations. E.g., a smaller coefficient is used for small deviations between $49.95 \sim 50.05 \mathrm{~Hz}$ under normal operation, and a bigger coefficient is used for large deviations $(>0.05 \mathrm{~Hz})$ to ensure as many DFR units as possible to be activated. In this paper, only single coefficient is considered, and more advanced design will be investigated in the future. Similar control can be applied for the cooling appliances like refrigerators or freezers, though slight changes may be necessary due to, e.g., only the lower temperature set point can be varied for industrial freezers. 
TABLE III

DESIGN CONSIDERATIONS FOR KEY PARAMETERS $\left(f_{o f f}, f_{\text {on }}, t_{o f f}, t_{o n}\right)$

\begin{tabular}{|c|c|c|}
\hline \multicolumn{2}{|c|}{$\begin{array}{c}\text { DFR } \\
\text { Parameter }\end{array}$} & Design considerations \\
\hline \multirow{4}{*}{$\begin{array}{l}\text { Type } \\
\text { I }\end{array}$} & $f_{o f f}$ & $\begin{array}{l}\text { According to targeted reserve, e.g. } 49.90 \mathrm{~Hz} \text { or below for the } \\
\text { disturbance reserve in the Nordic system } \\
\text { - Randomized for proportional activation of many appliances } \\
\text { - Appliances wear outs }\end{array}$ \\
\hline & $f_{o n}$ & $\begin{array}{l}\text { - Ensure frequency recover to the normal range e.g. [49.90, } \\
50.10] \mathrm{Hz} \text { for the Nordic system } \\
\text { - Different from disconnection setpoint for a dead-band and } \\
\text { prevent oscillatory behaviors, e.g. } 49.92 \mathrm{~Hz} \\
\text { - Randomized for asynchronous reconnection of many } \\
\text { appliances } \\
\text { - Appliances wear outs }\end{array}$ \\
\hline & $t_{\text {off }}$ & $\begin{array}{l}\text { - Due to frequency measurement and should be as short as } \\
\text { possible for fast response } \\
\text { - Consider if appliances can be switched frequently or not, } \\
\text { since many low frequency events are short in duration, and } \\
\text { intervals between events sometimes can be very short }\end{array}$ \\
\hline & $t_{o n}$ & $\begin{array}{l}\text { Randomly distributed for many DFR appliances to prevent } \\
\text { simultaneous reconnections. Some appliances require a } \\
\text { resting period, e.g. 5-30 minutes. A (too) long delay may } \\
\text { cause instability. }\end{array}$ \\
\hline $\begin{array}{c}\text { Type } \\
\text { II }\end{array}$ & $k f$ & $\begin{array}{l}\text { - Ensure as many appliances as needed be off when frequency } \\
\text { falls below certain limit e.g. } 49.90 \mathrm{~Hz}\end{array}$ \\
\hline
\end{tabular}

\section{Design Considerations}

Types I and II are different in many aspects. Type I can guarantee to turn off all DFR loads when frequency below the setpoint, and the reserve can be proportionally activated using randomized setpoints. However, Type I can only provide up regulation, i.e., turn off loads, though advanced design can be developed in the future. Type II is only appropriate for thermostatically controlled appliances or those with set-point control, e.g., pumping. It can provide continuous and proportional reserves for both under- and over-frequency. Because of aggregation, the number of disturbed customers is reduced. The DFR control parameters should be carefully designed, taking into account the power system requirements, e.g., the activation set point for reserves; the electric appliance itself, e.g., the wear outs; and the customer comforts.

Customer comforts are less concerned, because the durations of low frequency events are normally very short, e.g., average $0.8 \mathrm{~s}$ for events $<49.90 \mathrm{~Hz}$ in the Nordic system [2]. Customers usually have a longer tolerance for service interruptions subject to comfort and safety requirements which needs detailed studies. Nevertheless, interruptions up to $1 \mathrm{~h}$ and several minutes are usually acceptable for electric heating and refrigerators, respectively [13], [35]. Furthermore, too high $k f$ or $f_{\text {off }}$ will cause excessive wear outs. This can be taken care by optimizing control parameters based on, e.g., analyzing operational data but is not focused herein. Preliminary analysis for Type I appliance using the PMU frequency data has shown that the wear outs can largely be reduced by properly selecting the parameters including $f_{o n}, f_{o f f}, t_{o n}, t_{o f f}$, and the filter length. For appliances with cyclic operations such as electric heaters, wear outs are less important, and the power system requirement is the major concern. Table III summarizes the major design considerations that have been taken care in modeling the DFR appliances in Section IV.

\section{MODEL IMPLEMENTATION}

Electric heating appliances are focused in developing DFR simulation models. This is because plenty of heating demands exist in the Nordic system. Moreover, the district heating systems are suggested to be retrofitted or replaced by electric heating in the future in Denmark [27]. The switching flexibility and less disturbing impacts to customers also make them attractive for the application.

Statistical approach based on the state queuing theory can be used to model the aggregated appliances [28], [29]. Though efficient for computation, specific appliance behavior cannot be simulated by such a model, and the DFR control logic is difficult to be implemented. In this paper, a simulation model containing explicitly thermodynamics and the control logics have been developed. It consists of a general physics based simulation model in (6), the hysteresis in (7), as well as the control logics described in Section III:

$$
\begin{aligned}
& C \frac{d T}{d t}+G\left(T-T_{a}\right)+P_{\text {disturbance }}=w * P \\
& \text { if } T \geq T_{\text {high }}, \quad w=1-\text { "on" } \quad \text { stage } \\
& \text { if } T \leq T_{\text {low }}, \quad w=0-\text { "off" } \quad \text { stage } \\
& \text { Else remain unchanged }
\end{aligned}
$$

where $C$ is the heat capacity of the heating mass; $G$ is the thermal conductance between heated and non-heated mass; $\boldsymbol{P}$ is the rated power; $\boldsymbol{T}$ is the temperature of the heated mass; $\boldsymbol{T}_{a}$ is the ambient temperature; $\boldsymbol{P}_{\text {disturbance }}$ is the external disturbance due to, e.g., customer influence by door open/close, and voltage fluctuations in power grids that may increase or decrease the power consumption; $\boldsymbol{w}$ models the hysteresis. The temperature set point, i.e., the midpoint of $\boldsymbol{T}_{\text {high }}$ and $\boldsymbol{T}_{\text {low }}$, is determined according to heater types, e.g., 20 and $55^{\circ} \mathrm{C}$ for space and water heaters, respectively. $\boldsymbol{T}_{\text {high }}$ and $\boldsymbol{T}_{\text {low }}$ are assumed 2 degrees different for all heaters.

Although the modeling approach may increase the computational burden, individual appliance behaviors and their aggregated impacts can be simulated. The model is implemented in the DIgSILENT Power Factory [30]. It was initially designed to contain as many heaters as possible. As a compromise between the computing speed and appliances diversity, 500 different heaters are computed. A scaling factor as a coefficient to multiply with the power output of the DFR model is introduced to allow flexible manipulation of the total power, so that more heaters can be represented. These heaters are divided into five groups of 100 units to represent water and spaces heaters with different characteristics. Within one model, heater parameters such as the rated power and heating capacity are diversified. Furthermore, the uncertainties of initial heater temperature $\left(\boldsymbol{T}_{0}\right)$ and power on/off status $\left(\boldsymbol{w}_{0}\right)$ are modeled according to different distributions as shown in Table IV. Without scaling, the installation capacity of one DFR model is about 2.0 MW. Note that in the simulation studies, the heater parameters $C, G$, and $P$ are empirically selected to ensure close resemblance of the reality. Fine tuning these parameters according to actual products is underway in collaborations with industrial partners. The voltage dependency is not included in current model but can be implemented later on [31]. 
This article has been accepted for inclusion in a future issue of this journal. Content is final as presented, with the exception of pagination.

TABLE IV

APPLIANCES DIVERSITY AND UNCERTAINTIES

\begin{tabular}{c|l}
\hline \hline Parameter & \multicolumn{1}{|c}{ Modelling methods } \\
\hline$C$ & Normal distribution \\
$G$ & Normal distribution \\
$P$ & Normal distribution \\
$P_{\text {disturbance }}$ & White noise \\
$w_{0}$ & Randomly chosen e.g. $30 \%$ of units 'on' initially \\
$T_{0}$ & Rand $\left[\boldsymbol{T}_{\text {low }}, \boldsymbol{T}_{\text {high }}\right]^{*}$ \\
\hline
\end{tabular}

*Note: Rand stands for random (uniform) distribution function

TABLE V

Key DFR PARAMETERS IN SimUlation CASES

\begin{tabular}{l|l|r}
\hline \hline Test objective & \multicolumn{1}{|c|}{ Type $I_{a}$ and $I_{b}$} & Type $I I$ \\
\hline & $f_{\text {off }}: \operatorname{Rand}[49.85,49.90] \mathrm{Hz}$ & \\
Disturbance & $f_{\text {on }}: 49.95 \mathrm{~Hz}$ & $k_{f}=20^{\circ} \mathrm{C} / \mathrm{Hz}$ \\
reserve & $t_{\text {off }}: 0.4 \mathrm{~s}$ & \\
& $t_{\text {on }}:$ Rand $[4,6]$ min & $k_{f}=20^{\circ} \mathrm{C} / \mathrm{Hz}$ \\
\hline Normal reserve & Not considered &
\end{tabular}

In Section V, the DFR model will be tested as disturbance and normal reserves. Table $\mathrm{V}$ gives the key DFR parameters used in the test which are determined mainly according to purpose of study and other considerations as discussed in Section III. Note the $k f$ is determined such that $0.1-\mathrm{Hz}$ change in frequency can result in activation of all DFR appliances, i.e., the temperature set point is changed by $2^{\circ} \mathrm{C}$.

\section{NUMERICAL SimULATIONS}

The DFR behavior and their impacts to system and customers in response to frequency variations will be evaluated through simulations. The power system models of the Nordic system supplied by Danish TSO Energinet.dk, and the Danish island Bornholm system are used.

\section{A. Nordic System Case}

The Nordic system model consists of 320 buses (mainly at $300,400 \mathrm{kV}$, etc), and 125 synchronous generators. The total system demand is $40 \mathrm{GW}$ in our case studies. The peak demands of Nordic system and Eastern Denmark are about $70 \mathrm{GW}$ and 3.3 GW, respectively. Five DFR models, i.e., 2500 heaters, are connected at circled buses in Fig. 6. A scaling factor of 100 is applied to the DFR models. The connecting buses are selected among major load buses in the system. The total installation capacity for DFR loads is $1000 \mathrm{MW}$, amounting to $<2.5 \%$ of total system demand, which may not reflect the reality. The actual volume of heating loads can be higher, e.g., $62 \mathrm{MW}$ for Eastern Denmark alone which is a fairly small portion $(<5 \%$ in terms of peak demand) of the system. Therefore, relevant results from this case can be considered conservative. Four cases of the heaters with three types DFR controls, and without control are simulated. In order to study the impact of DFR load location, an additional case with all type II loads concentrated at the central bus of circled ones in Fig. 7 is simulated, of which the result can indicate if connecting DFR loads to one bus instead of many is appropriate, in order to reduce the modeling workload. All simulations run for $50 \mathrm{~min}$ with a contingency of $500-\mathrm{MW}$ generation outage at $t=1500 \mathrm{~s}$. The simulation duration is determined long enough to cover more than two cycles of most heaters.
Fig. 7 shows the frequency and consumption (scaled) of $20 \%$ heaters units (i.e., one DFR model). Before the contingency, the system is stable, and system frequency and total consumptions of heaters differ very sightly for all cases. During the contingency, the magnitude and duration of frequency dip is effectively reduced due to the DFR. Because of different controls, Type II has the largest consumption reduction, irrespective of concentrated or distributed cases. Types $I_{a}$ and $I_{b}$ has similar performance during the event, but differ in the reconnection stage later on. All types fulfill the design requirements by having smooth consumption returns. However, type $I_{b}$ has a relatively slower and smaller return while $I_{a}$ has a faster and larger one, causing additional frequency variations though at small magnitude. Obviously, Type II outperforms others by instantaneous response to frequency drop, while type Is only react at the setpoint. Type II also reconnects smoothly right after the event while Type Is only starts at the reconnection setpoint and after the delay. Fig. 8 shows the first $60 \mathrm{~s}$ after the contingency where the lowest frequencies and observation times are denoted. Fig. 9 compares the frequency statistics for different cases where the DFR performance as the disturbance reserve especially for Type II is confirmed again. Notice the different reconnections of Type $I_{a}$ and $I_{b}$ only cause little discrepancies in the resultant statistics.

The impact of DFR control to individual appliance is important for customers' comforts. In Fig. 10, the top and middle plots are the on-off cycles of the same heater unit in all cases. Comparing the DFR disabled case (top) to the enabled cases (middle), it is clear that DFR controls will not stop the appliances infinitely, so as for the comforts to customers, in events of contingency. Instead, they will coordinate the operation cycles of heaters in a better way, in order to help recover the frequency. The limited impact to the customers is further confirmed by examining the average heater temperature. The bottom plot shows that the average temperature variation of all water heaters stays well within 2 degrees even after the contingency for all DFR enabled cases. Average temperature so as the customer comfort is affected mostly for Type II case. Certainly without DFR, the little variation is observed.

\section{B. Bornholm System Case}

Located in the Baltic Sea, the power system at the Bornholm island is a typical Danish distribution grid with substantial wind power. From time to time, the cable connection to Sweden is disrupted by ship anchors, resulting in islanding operations up to several months, during which most wind turbines have to be shut down due to the difficulty in stabilizing the frequency. The Bornholm-type problem has been regarded representative for distribution systems with substantial wind power, particularly relevant for Denmark with a goal of 50\% wind penetration by 2025. The DFR technology has been therefore regarded as a possible solution with high potential.

The supplied system model is still preliminary yet to be validated. Therefore, the simulation results of this case will be preliminary, but still can serve the purpose to verify that Type II DFR can work as normal reserve during normal operation with wind power. The model consists of 18 busbars at $60 \mathrm{kV}, 19$ busbars at $10 \mathrm{kV}$, five generators at $60 \mathrm{kV}$, and one sea cable to 


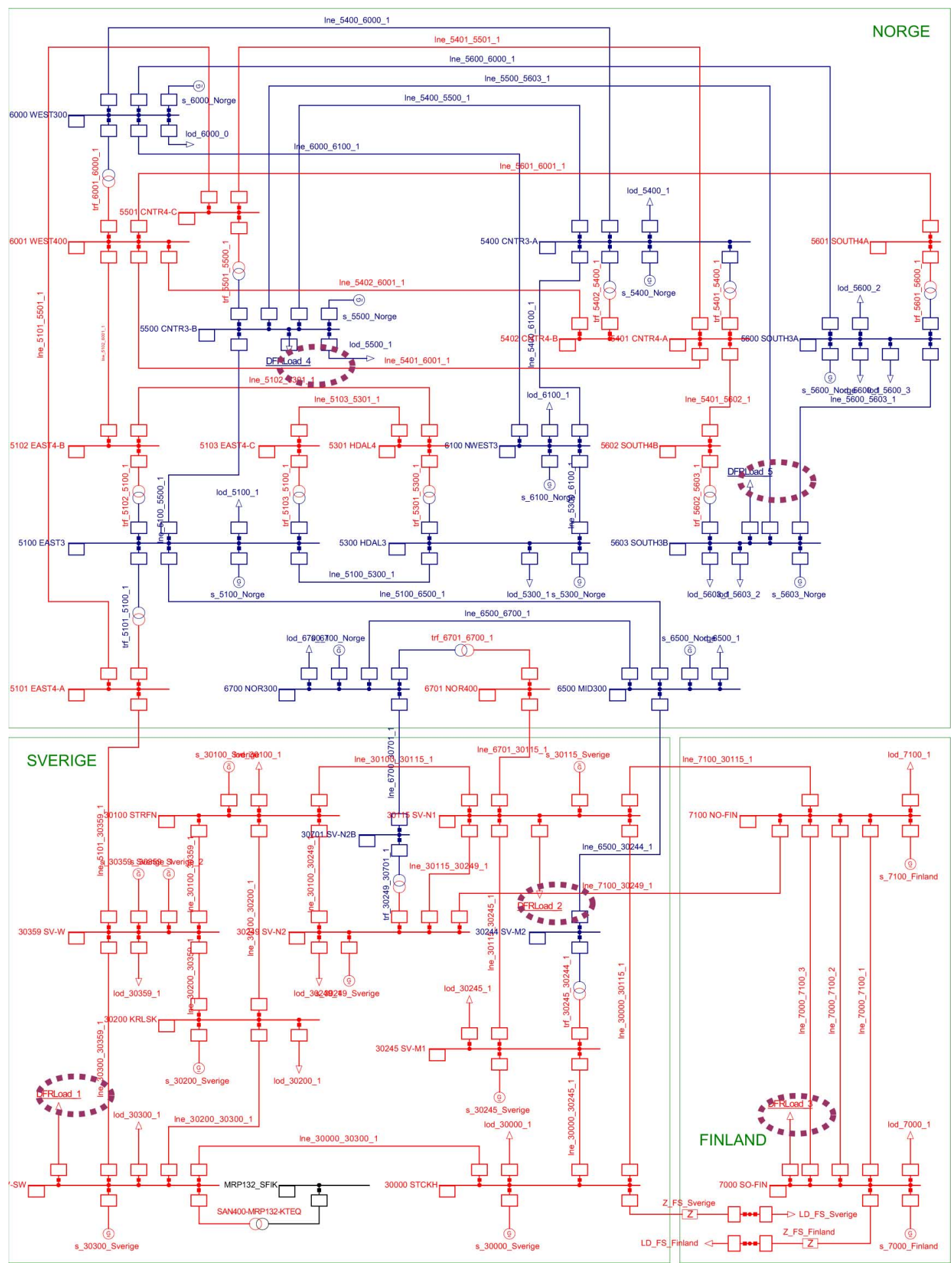

Fig. 6. Nordic system model in Power Factory (the Eastern Danish grid is not shown, and the circles denote where the DFR loads installed).

Sweden. Fig. 11 shows the $60-\mathrm{kV}$ network structure at Bornholm including substations.

A 2-MW fixed speed induction generator (FSIG) type wind turbine is included in the model without smoothing effect. The wind turbine contains modules of aerodynamics and two mass shaft models. The parameters are taken from available information [32], [33]. Actual wind speed data measured at 1/8-s interval is fed into the FSIG during the simulation [34]. The total system demand without DFR heaters is constant at $45 \mathrm{MW}$. Therefore, the disturbance in this study is mainly caused by the wind turbine with minor contributions from DFR heaters due to their cyclic operations. Since the connecting point is less important according to the Nordic case, all heaters are all connected to one of the major load buses at $60 \mathrm{kV}$. Cases with the DFR heaters scaled from $0-10 \%$ of total system demand are simulated for $1000 \mathrm{~s}$ for the islanded operation. All cases result in 

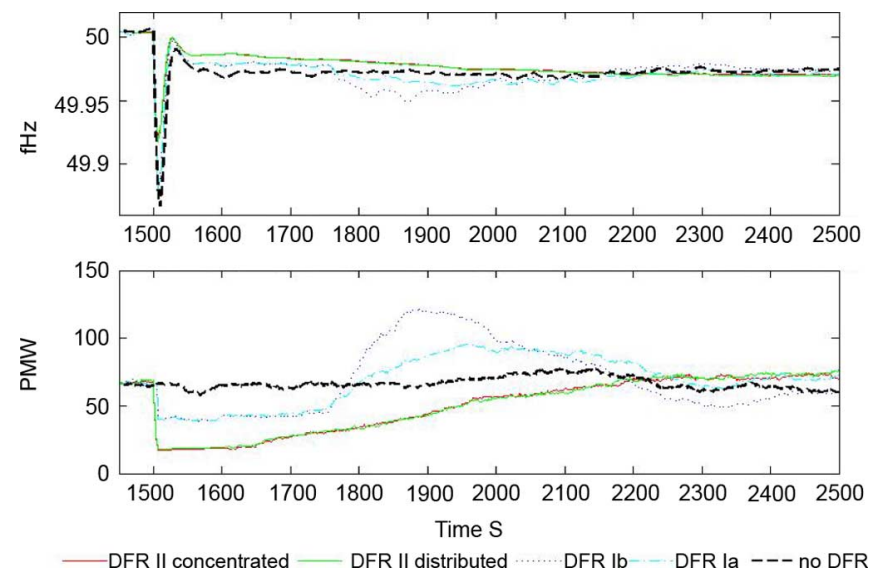

Fig. 7. System frequency and the demand of $20 \%$ heaters during the contingency.

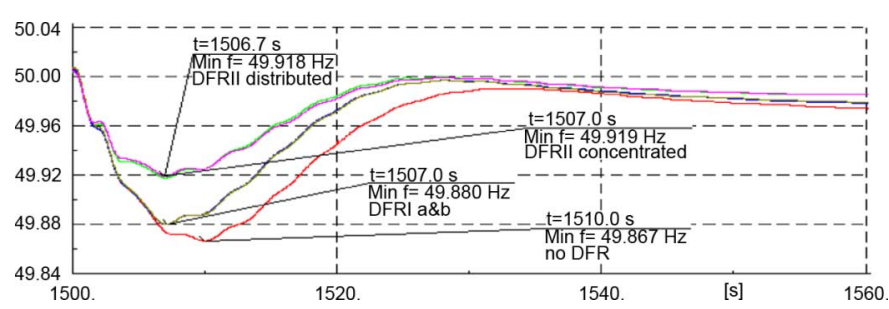

Fig. 8. Zoom-in plot of system frequency during the contingency.

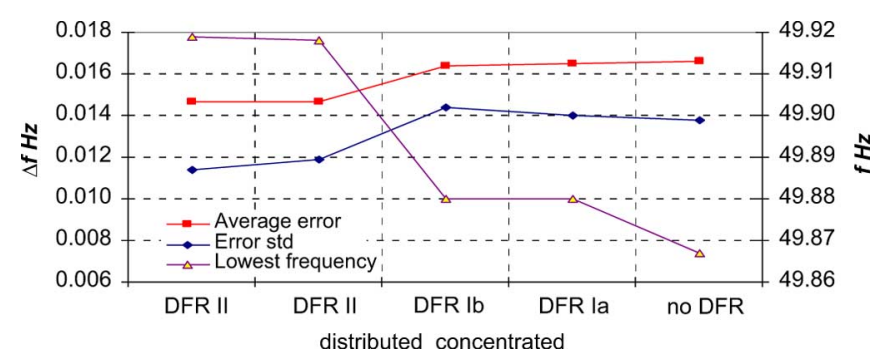

Fig. 9. Frequency statistics of different cases.
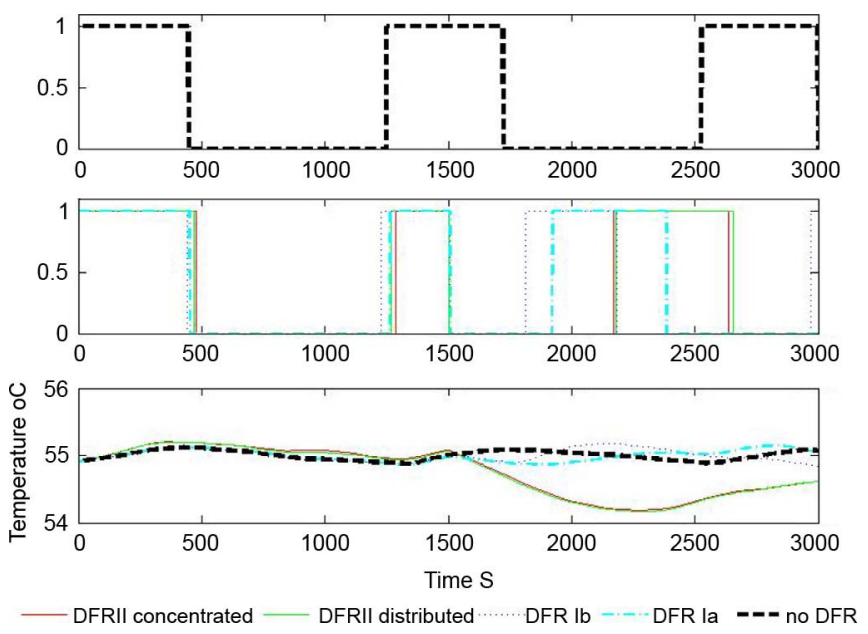

Fig. 10. Operation cycles and the average temperature of heaters (the top shows the operation cycle of one heater with no DFR; the middle shows the operation cycle of the same heater for cases of DFR II concentrated, DFR II distributed, DFR Ia and DFR Ib, respectively; the bottom shows the average temperature of 100 water heaters in all cases).

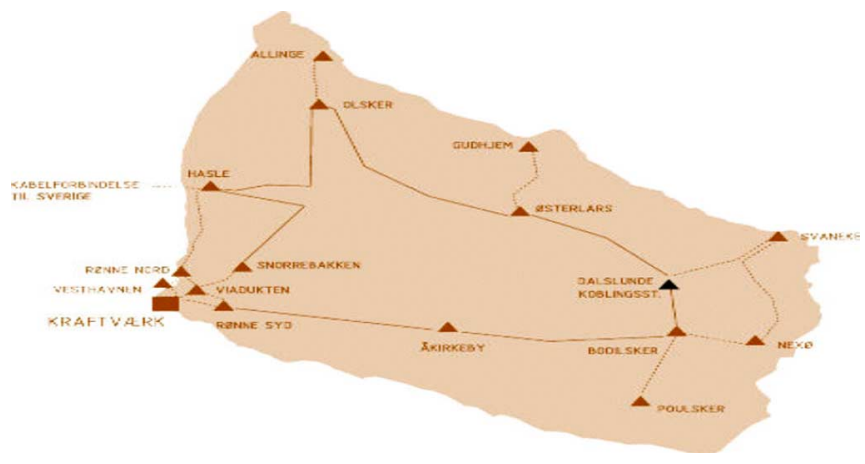

Fig. 11. Bornholm 60-kV network structure.

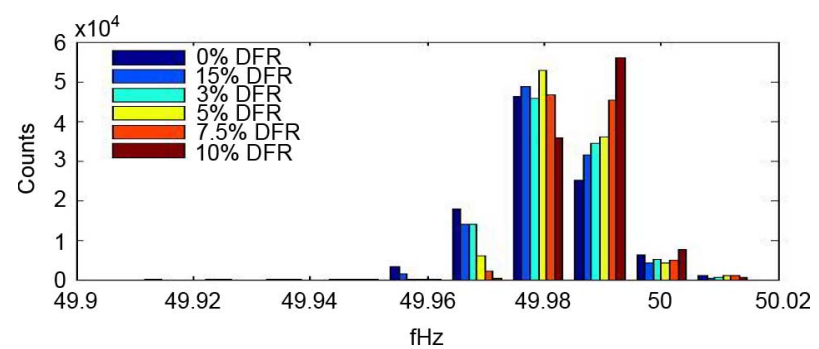

Fig. 12. Histogram of simulated frequency in the Bornholm case.

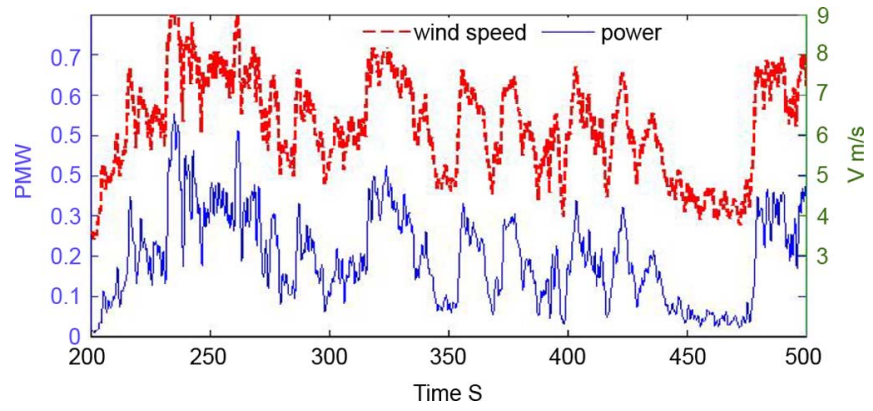

Fig. 13. Wind speed and the wind turbine power output.

satisfactory frequencies within $[49.90,50.10] \mathrm{Hz}$, but with different quality. Fig. 12 proves the proportional relationship between the amount of DFR load and the benefit to system frequency control, as the higher the DFR load percentage is, the closer the frequency is distributed around $50 \mathrm{~Hz}$. Fig. 13 takes a 5-min window of the wind speed and turbine production with serious fluctuations, and Fig. 14 shows the resultant system frequency (top) and aggregated response (middle) from all heaters during the same period. The bottom figure shows that the total generation reserve has been effectively saved by activating the DFR heaters, and such saving is also proportional to the DFR percentage.

\section{Summary}

In summary, the DFR proves to be a stable technology when integrated with large and small power systems. During the contingency condition in the Nordic case, the type II outperforms others due to continuous regulation, therefore being more effective for frequency control, while type Is only disconnect at the set points. After the contingency, type II demand returns very smoothly right away, while type Is demand will not return due 

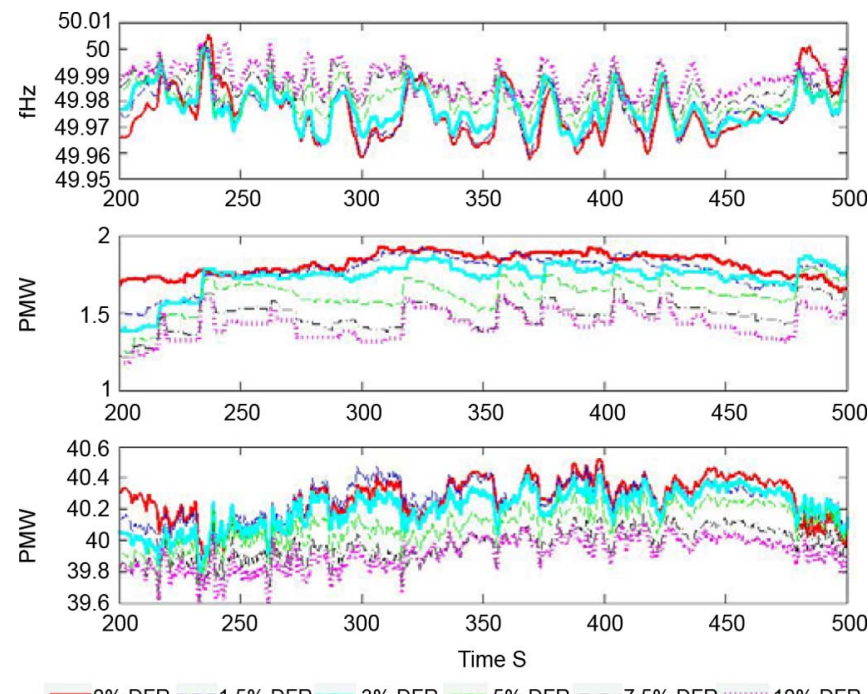

Fig. 14. System frequency (top), DFR heaters power output (middle), and the aggregated response of the generators with frequency control.

to the set points and delays that can prevent simultaneous reconnection of many loads. Type II also performs well as normal reserve for normal operation of Bornholm power system with wind power, and the benefit to frequency control appears proportional to its percentage out of total system demand. It is also noticed the DFR control will not stop appliances forever, so as for the customer comforts, rather it coordinates operations of many demands to enhance frequency control. The locations of DFR loads seem to have little impact on their performance.

\section{DISCUSSION AND CONCLUSION}

The DFR is an emerging technology which allows demands to participate actively in system operation without reducing the energy service delivered to the customer and without need of user interaction. The basic premise is that traditional reserves from power plants and HVDC may not fulfil the need of future power grids with substantial wind power, where reserves with lower cost and faster response are preferred. Electricity demands, on the other hand, have advantages including fast reaction, smooth activation, low expected costs, and well-dispersed in the distribution grid.

This paper has investigated use of DFR technology to provide frequency reserve to power systems. The potential and economy of DFR compatible loads in Denmark has been studied. The available volume of compatible loads is larger than required reserves and the cost of implementing the technology is low. Several control logics have been designed based on analysis of various design considerations such as power system requirements and customer impacts. The power system impacts of DFR have been investigated through modeling and simulations, revealing a reliable performance for frequency control. The critical challenges facing practical implementation of such technology include the monitoring issue and a feasible market model.

Real-time monitoring is suitable for large power plants that can afford dedicated communications to power system operator. Accurate monitoring of reserves from many small sized, autonomous appliances is economically impractical and technically unnecessary. The DFR is comparable to the self-regulation of load frequency dependency taken into account today, which is estimated rather than monitored. Monitoring in case of many DFR units can be achieved by estimation based on, e.g., statistical sampling of a limited number of such appliances [21], [35], [36]. Such a monitoring method may require the current reserve monitoring practice to extend to specify the quality requirements including accuracy of the amount and availability. The business model could be either implemented through a fixed rebate of the products subsidized by power system operators or in a market approach, e.g., participate in the regulation market in the Nordic system. Communication may be included but not necessarily needed for business implementation, e.g., the amount of reserve can be recorded by storage devices, and sent to system operator later through the Internet. The cost of having communication could be reduced by utilizing existing communication system in home automation and other systems, and combining DFR with other technologies such as the price and voltage responsive demands [35], [37].

Our next research step will probe further into above issues as well as others, such as using DFR to facilitate intentional islanding operation of distribution grids. Furthermore, a field demonstration project of the DFR technology is currently ongoing at the Technical University of Denmark in collaboration with manufacturers and utilities. It is expected that more results will be reported by the end of the project.

\section{REFERENCES}

[1] Nordel, Nordic Grid Code, 2007.

[2] Z. Xu, J. Østergaard, and M. Togeby, Demand as Frequency Controlled Reserve-Final Report of the PSO Project, Technical University of Denmark and Ea Energy Analyses, 2008.

[3] Z. Xu, J. Østergaard, M. Togeby, and C. Marcus-Møller, "Design and modeling of thermostatically controlled loads as frequency controlled reserve," in Proc. 2007 IEEE PES General Meeting.

[4] Danish Ministry of Transport and Energy, Energistrategi 2025 (Energy Strategy 2025), 2007

[5] Nordel, Power and Energy Balances Forecast 2008, 2007.

[6] J. D. Kueck, B. J. Kirby, J. Eto, R. H. Staunton, C. Marnay, C. A. Martinez, and C. Goldman, Load as a Reliability Resource in Restructured Electricity Markets, ORNL/TM2001/97. LBNL-47983. Oak Ridge, TN: Oak Ridge Nat. Lab., 2001.

[7] M. Bailey, "Provision of frequency responsive power reserve from disconnectable load," Proc. IEE Colloq. Economic Provision of a Frequency Responsive Power Reserve Service (98/190), pp. 5/1-5/5, Feb. 1998.

[8] A. Turner, T. N. Chan, and A. N. Gibbs, "A fast reacting power system load shedding management system," in Proc. 9th Conf. Electric Supply Industry (CEPSI), Hong Kong, 1992.

[9] Fingrid, Maintenance of Frequency. [Online]. Available: http:// www.fingrid.fi/portal/in_english/services/system_services/maintenance of frequency.

[10] B. J. Kirby, Spinning Reserve Provided From Responsive Loads. Oak Ridge, TN: Oak. Ridge Nat. Lab., 2003.

[11] M. Kintner-Meyer, R. Guttromson, D. Oedingen, and S. Lang, Final Report for California Energy Commission: Smart Load and Grid-Friendly Appliances, Architecture Energy Corporation and Battelle Memorial Institute, 2003.

[12] PNNL, Grid Friendly ${ }^{\mathrm{TM}}$ Controller Helps Balance Energy Supply and Demand. [Online]. Available: http://www.gridwise.pnl.gov/docs/ pnnlsa36565.pdf.

[13] J. A. Short, D. G. Infield, and L. L. Freris, "Stabilization of grid frequency through dynamic demand control," IEEE Trans. Power Syst., vol. 22, no. 3, pp. 1284-1293, Aug. 2007.

[14] A. Angel, F. Bouffard, and D. Kirschen, "Decentralized demand-side contribution to primary frequency control," IEEE Trans. Power Syst., to be published. 
[15] D. Hirst, The Demand Side-Teaching an Old Dog New Tricks. London, U.K.: Responsive Load Limited, 2006.

[16] F. C. Schweppe, "Frequency Adaptive, Power-Energy Re-Scheduler," United States Patent 4317049, 1979.

[17] Nordic Energy Regulators (NordREG), Monitoring of the Nordic Regulation Power Market, 2007.

[18] B. Bakken and A. Petterteig, "Reserve requirements and security of supply," in Proc. Sintef. Capacity Shortage Seminar, Gardemoen, Norway, Apr. 2005.

[19] The Nordic Model. [Online]. Available: http://www.nordpoolspot. com/PowerMaket/.

[20] Nordel, Activating Price Elastic Demand at High Prices, 2004.

[21] Priselastik Elforbrug hos de Større Elforbruger (Demand Response at Large Electricity Consumers), Dansk Energi Analyse and Norenergi, 2005.

[22] A. H. Nielsen, K. O. H. Pedersen, P. Jørgensen, J. Havsager, S. K. Olsen, and J. Rasmussen, "Phasor measurement units in the eastern Danish power system," in Proc. CIGRE Conf. 2006, Paris, France, 2006, pp. 1-5.

[23] O. Samuelsson, M. Hemmingsson, A. H. Nielsen, K. O. H. Pedersen, and J. Rasmussen, "Monitoring of power system events at transmission and distribution level," IEEE Trans. Power Syst., vol. 21, no. 2, pp. 1007-1008, May 2006.

[24] High Performance Computing Systems, Technical University of Denmark. [Online]. Available: http://www.gbar.dtu.dk.

[25] C. Marcus-Moller, Demand as Frequency Controlled Reserve-Analysis of Technology and Potentials Student Project Report, Technical University of Denmark, 2006.

[26] Energinet.dk, Øvrige Systemtjenester (Other System Services), 2007.

[27] Energinet.dk, Efficient Use of Wind Power-Based Electricity in Denmark-Interaction Between Wind Power, Heat Pumps and Electric Vehicles, 2009.

[28] N. Lu and D. P. Chassin, "A state-queueing model of thermostatically controlled appliances," IEEE Trans. Power Syst., vol. 19, no. 3, pp. 1666-1673, Aug. 2004.

[29] N. Lu, D. P. Chassin, and S. E. Widergreen, "Modelling uncertainties in agrregated thermostatically controlled loads using a state-queueing model," IEEE Trans. Power Syst., vol. 20, no. 2, pp. 725-733, May 2005.

[30] DIgSILENT, Power Factory User Manual Version 13.2, 2007.

[31] P. Kundur, Power System Stability and Control. New York: McGrawHill, 1993.

[32] V. Akhmatov, Induction Generators for Wind Power. Brentwood, U.K.: Multi-Science, 2005.

[33] Wind Power in Power Systems, T. Ackermann, Ed. New York: Wiley, 2004.
[34] DTU Database of Wind Characteristics. [Online]. Available: http://www.winddata.com/.

[35] C. Kofod and M. Togeby, "Demand response offered by households with direct electric heating," in Proc. Demand Response in Energy Markets Conf., Nordic Energy Research, Nov. 26, 2004.

[36] Elmodel Bolig. [Online]. Available: http://www.elmodelbolig.dk/.

[37] R. Garcia-Valle, L. C. Da Silva, Z. Xu, and J. Østergaard, "Smart demand for improving short-term voltage control on distribution networks," IET Proc. Gen., Transm., Distrib., vol. 3, no. 8, pp. 724-732, 2009.

[38] C. Bäck, "Svenska Kraftnät: Current balancing methods in Nordel area," in Proc. ENTSO-E Meeting, Mar. 8, 2010.

[39] Nordel Annual Statistics, 2008. [Online]. Available: https://www. entsoe.eu/index.php?id=65.

Zhao Xu (S'00-M'06) received the Ph.D. degree in electrical engineering from University of Queensland, Brisbane, Australia, in 2006.

From 2006-2009, he was an Assistant Professor and later an Associate Professor at the Centre for Electric Technology, Technical University of Denmark, Lyngby. Since 2010, he has been with the Department of Electrical Engineering, Hong Kong Polytechnic University. His research interests include demand side, electric vehicles to grid, grid integration of wind power, electricity market planning and management, and $\mathrm{AI}$ applications.

Jacob Østergaard (M'95-SM'09) is a Professor and Head of Centre for Electric Technology, Department of Electrical Engineering, Technical University of Denmark, Lyngby. His research interests include integration of renewable energy, control architecture for future power system, and demand side.

Professor Østergaard is serving in several professional organizations, including the EU SmartGrids advisory council.

Mikael Togeby received the M.Sc. and Ph.D. degrees from the Technical University of Denmark, Copenhagen, in 1983 and 1988, respectively. He is now Partner of Ea Energy Analyses A/S, Denmark. He has a long record of consultation service in electric energy industries. His interests include demand response, energy efficiency, and electricity market.

Dr. Togeby is a member of several professional organizations, including the International Association for Energy Economics and the European Council for an Energy Efficient Economy. 